\title{
Comparação da ultra-sonografia com a flebografia e a morfologia no trombo venoso recente - estudo experimental em cães
}

\author{
Comparison of ultrasonography with venography and morphology \\ in recent venous thrombus - experimental study in dogs
}

\section{M ariangela Giannini*}

Introdução: 0 diagnóstico da trombose venosa profunda sintomática com o ultra-som ébastante acurado, en quanto que, natrombosevenosa profundarecenteeassintomática, ainda não está bem estabelecido.

O bjetivo: 0 objetivo deste trabalho foi verificar a sensibilidade, especificidade e acurácia do ultra-som com a utilização do modo B, da compressão da veia com o transdutor, daimagem com harmônicadetecidos, aval iação dediâmetros da veia em relação à artéria, cor, power Doppler, curva D oppler e B flow, quando comparados com a flebografia eo exame morfológico da verificação cirúrgica, no diagnóstico da trombose venosa profunda recente em estudo experimental em cães.

M étodos: Vintecãesforam divididospor sorteio em dois grupos: grupo controle e grupo com trombose. $\mathrm{N}$ o grupo com trombose, a cava inferior foi exposta cirurgicamente, ea trombose foi induzida pela injeção de trombina em um segmento isolado, por 10 minutos, entre duas pinças cirúrgicas. No grupo controle, os animais foram submetidos aos mesmos procedimentos cirúrgicos, sem a indução da trombose. 0 ultra-som foi realizado no pré e pós-cirúrgico (2 horas apósaindução datrombose). A flebografiafoi realizada imediatamente antes do ultra-som pós-cirúrgico. Após o segundo ultra-som, foi real izada cirurgia para a verificação da presença ou não detrombo. Foram comparadosos resultados do ultra-som com a flebografia e a verificação cirúrgica da presença do trombo.

Resultados: Em todos os cães, os segmentos da cava inferior eram compressíveis com o transdutor. Asrelações do diâmetro dacavainferior com aortaforam maiores $(P<0,005)$ no grupo com trombose do que no grupo controle. 0 ultrasom com a utilização de imagem com harmônica, power D oppler, curva D oppler na respiração espontânea e B flow teve sen sibilidade, especificidadee acurácia de 1 . A flebografia apresentou sensibilidade de $90 \%$, especificidade de $80 \%$ eacurácia de $85 \%$, quando comparada com o exame morfológico do achado cirúrgico.

C onclusões: No diagnóstico da trombose venosa profundarecente, no model o experimental utilizado, a compressão da veia com o transdutor não se mostrou eficaz. A relação do diâmetro decava inferior com aorta, quando aumentado, pode sugerir a presença de trombose. A utilização, no ultrasom, de novos avanços tecnológicos aumenta a acurácia. A flebografia foi menos acurada que o ultra-som.

\footnotetext{
* Professora assistente da Disciplina de Cirurgia Vascular, Departamento de Cirurgia e Ortopedia, Faculdade de Medicina de Botucatu (FMB), Universidade Estadual Paulista (UNESP), Botucatu, SP.

Orientador: Prof. Dr. Hamilton Almeida Rollo.

Apresentação: 04/05/2005 na Faculdade de Medicina de Botucatu - UNESP.

Banca examinadora: Prof. Dr. Hamilton Almeida Rollo (FMB - UNESP), Prof. titular Francisco Humberto de Abreu Maffei (FMB-UNESP), Prof. Dr. Fausto Miranda Jr. (Universidade Federal de São Paulo - UNIFESP), Prof. Dr. Carlos Alberto Engelhorn (Pontifícia Universidade Católica do Paraná - PUCPR),

Prof. Dr. Domingos de Morais Filho (Universidade Estadual de Londrina - UEL).
}

Correspondência: Mariangela Giannini

Departamento de Cirurgia e Ortopedia. Faculdade de Medicina de Botucatu - UNESP

CEP 18618-970 - Botucatu, SP - Tel.: (14) 3811.6269/3811.6092 - Fax: (14) 3815.7428 - E-mail: marigiannini@uol.com.br 